\title{
Kegiatan kesyahbandaran di pangkalan pendaratan ikan Kema di Minahasa Utara
}

\author{
Fish port authority activities in fish landing base of Kema, North Minahasa \\ Arthur W. E. Rante Padang, Alfret Luasunaung dan Mariana E. Kayadoe \\ Program Studi Pemanfaatan Sumberdaya Perikanan, Fakultas Perikanan Dan Ilmu Kelautan, \\ Universitas Sam Ratulangi, Manado 95115
}

\begin{abstract}
Kema is one of the districts in North Minahasa Regency, which has a Fish Landing Base and also a local fish port area supplying marine fish. Kema Fish Landing Base is very helpful for Kema people in fish marketing. Fish port authority has a duty to check the document completeness and validity, the technical and nautical requirements of the ship for safety consideration, and set the cruise line inside the port area. The importance of the authority's role in relation with the cruise safety is provided in Indonesian Law Numbered 17, 2008, concerning sailing cruise. The purpose of this study is to find out the obstacles encountered by the sahbandar and evaluate these constraints for the smooth running of the task. The research used descriptive method through interviews. Results showed that the port authority's working performance in Kema was good.
\end{abstract}

Keywords: authority; fish landing base; document; ship; Kema.

\begin{abstract}
ABSTRAK
Kema adalah salah satu kecamatan di kabupaten Minahasa Utara, yang memiliki Pangkalan Pendaratan Ikan (PPI) dan juga merupakan pelabuhan perikanan lokal yang memasok ikan laut. Pangkalan Pendaratan Ikan Kema sangat membantu warga Kema untuk kelancaran proses penjualan ikan hasil tangkapan. Syahbandar perikanan memiliki tugas memeriksa kelengkapan dan keabsahan dokumen, memeriksa persyaratan teknis dan nautis kapal dari aspek keselamatan, dan mengatur alur pelayaran di dalam area pelabuhan. Pentingnnya peran syahbandar dalam keselamatan pelayaran yang tercantum pada undang-undang nomor 17 tahun 2008 tentang pelayaran. Tujuan penelitian ini yakni mengetahui kendala yang dihadapi syahbandar dan mengevaluasi kendala tersebut untuk kelancaran tugas. Penelitian ini menggunakan metode deskriptif dari data hasil wawancara. Hasil penelitian menunjukan bahwa tugas dan kinerja syahbandar Kema dapat digolongkan baik berdasarkan jawaban responden.
\end{abstract}

Kata-kata kunci: syahbandar; pangkalan pendaratan ikan; dokumen; kapal; Kema.

\section{PENDAHULUAN}

Pembangunan dan pemanfaatan sumberdaya kelautan yang tersimpan di wilayah perairan nusantara sampai saat ini sudah mendapat perhatian yang memadai sehingga semua aspek yang menunjang dalam pengelolaan perikanan bertanggung jawab perlu terus ditingkatkan agar sinergitas kerja antara masyarakat nelayan dan pemerintah dalam menjalankan kebijakan yang ada. Pelabuhan perikanan sebagai penyedia fasilitas operasional kapal perikanan memiliki peran yang cukup signifikan dalam mendukung kegiatan peningkatan perikanan laut. Dalam rangka peningkatan kinerja sebagai upaya keselamatan pelayaran yang aman, tertib, nyaman maka pemerintah Indonesia berusaha meningkatkan pula keselamatan pelayaran dengan membentuk organisasi syahbandar sebagai langkah maju dalam mengimbangi pelayanan dibidang pelayaran.

Syahbandar perikanan memiliki tugas memeriksa kelengkapan dan keabsahan dokumen, mengatur kedatangan dan keberangkatan kapal

\footnotetext{
*Penulis untuk penyuratan; email: arthurrantepadang @gmail.com
} 
serta mengatur pergerakan alur pelayaran dalam area pelabuhan. Tujuan penelitian ini untuk mengetahui kendala yang dihadapi kesyahbandaran di Pangkalan Pendaratan Ikan (PPI) Kema dan mengevaluasi kendala yang ada untuk kelancaran pelakasanaan tugas kesyahbandaran di Kema. Penelitian ini dilaksanakan di kantor kesyahbandaran PPI Kema Minahasa Utara, pada bulan Januari sampai bulan Februari 2019.

\section{METODOLOGI PENELITIAN}

Metode yang digunakan dalam penelitian ini adalah metode deskriptif yakni penggambaran suatu keadaan yang di hadapi oleh syahbandar di PPI Kema dalam pelaksanaan tugas keseharian. Pengumpulan data dilakukan dengan mencatat dokumen yang ada di PPI Kema berupa banyaknya kapal yang keluar (keberangkatan) dan kapal yang tiba (kedatangan) juga wawancara yang mendalam ke nelayan (Nakoda dan ABK). Untuk mencapai tujuan pertama, data (primer/sekunder) yang dikumpulkan melalui pencatatan, wawancara dan pengamatan langsung dianalisis secara deskriptif untuk menentukan kendala yang dihadapi syahbandar di PPI Kema dalam pelayanannya terhadap nelayan. Selanjutnya untuk mencapai tujuan kedua, dari kendala yang ada dievaluasi (solusi) agar pelayanan kepada nelayan lebih efektif dan efisien.

\section{HASIL DAN PEMBAHASAN}

Syahbandar adalah seorang pejabat yang memiliki wewenang untuk menentukan kelaikan kapal dalam berlayaran. Syahbandar yang ditempatkan pada suatu tempat tertentu guna memberikan rasa aman dalam pelayaran.

Menurut peraturan Menteri Perhubungan Nomor PM 82 Tahun 2014 tentang Surat Persetujuan Berlayar (SPB) adalah dokumen negara yang dikeluarkan oleh syahbandar untuk setiap kapal yang akan berlayar dan hanya berlaku selama 1x24 jam untuk sekali pelayaran.

Dilihat dari kegiatan syahbandar yang ada di PPI Kema, dalam setiap pengurusan SPB dilakukan dengan memeriksa beberapa dokumen kapal yaitu: Untuk kapal dengan ukuran 5-6 GT dokumen yang diperiksa oleh Syahbandar di Pangkalan Pendaratan Ikan Kema:

1. Daftar ABK (anak buah kapal)

2. Pas kecil
3. Buku kesehatan pelabuhan

4. Surat laik operasi (SLO) "untuk pemilik kapal yang memiliki lebih dari 1 kapal"

Untuk kapal dengan ukuran 7-10 GT dokumen yang diperiksa oleh Syahbandar di Pangkalan Pendaratan Ikan Kema

1. Pas besar

2. Buku kesehatan pelabuhan

3. Surat laik operasi (SLO)

4. Daftar ABK (anak buah kapal)

Untuk kapal dengan ukuran 11-30 GT dokumen yang diperiksa oleh Syahbandar di Pangkalan Pendaratan Ikan Kema:

1. Pas besar

2. Surat laik operasi (SLO)

3. Daftar ABK (anak buah kapal)

4. Buku sijil awak kapal

5. Buku kesehatan pelabuhan.

Tahapan kegiatan pelayanan syahbandar di PPI Kema diawali dengan permohonan pengurusan SPB oleh nelayan (sesuai ukuran GT kapal masingmasing), kemudian pengecekan di atas kapal sebagai berikut: Setelah semua kegiatan pengecekan di atas kapal selesai dilakukan dan kapal siap untuk berlayar yang dinyatakan dalam surat pernyataan kesiapan kapal berangkat dari nahkoda (master sailing declaration), maka berkas permohonan penerbitan SPB (port clearance) diserahkan kepada syahbandar. Setelah permohonan diajukan syahbandar melakukan pemeriksaan kelengkapan dan validasi dari surat dan dokumen kapal. Apabila kapal tidak memenuhi syarat administrasi maupun keamanan kapal SPB tidak dapat diberikan. Dan bagi pemilik kapal atau nakhoda kapal yang mengajukan permohonan, diperintahkan untuk melengkapi agar SPB dapat diterbitkan.

Kegiatan pelayanan pengurusan SPB yang diperoleh selang empat tahun terakhir (2015-2018) di PPI Kema ditunjukkan pada Gambar 1.

Berdasarkan hasil kajian kinerja syahbandar terhadap setiap kapal penangkap ikan tergolong cukup baik. Sedangkan faktor yang menjadi kendala dalam kinerja syahbandar yakni tidak adanya fasilitas penunjang seperti komputer dan printer. Akibat tidak adanya fasilitas penunjang tersebut, maka syahabandar lambat dalam pengurusan SPB. 


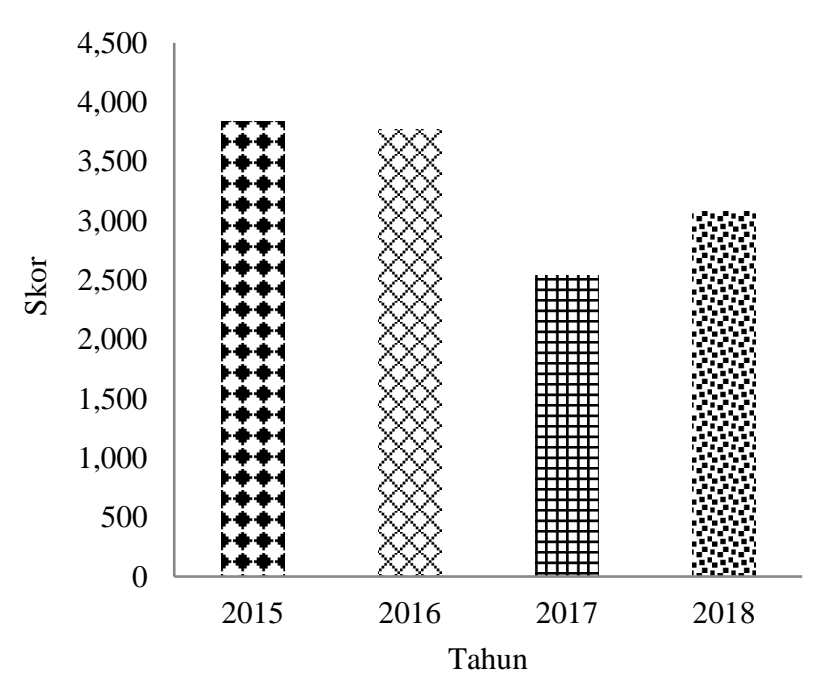

Gambar 1. Laporan wilayah kerja Syahbandar di PPI Kema, Tahun 2015-2018

Penilaian responden terhadap pelayanan syahbandar mengenai tugas syahbandar yang terdiri dari pengawasan setiap pembongkaran ikan hasil tangkapan, pengawasan setiap kapal keluar (berangkat) dan tiba (kedatangan), memeriksa kelengkapan alat keselamatan diatas kapal, memeriksa log book dan pengisian bahan bakar serta pengurusan surat untuk kembali melaut. Dilihat pada Gambar 2 penilaian responden yaitu sangat puas dengan jumlah presentase (42\%), namun ada beberapa responden tidak puas dengan pelayanan syahbandar yang ada di pangkalan pendaratan ikan (PPI) Kema dengan presentase (8\%). Dapat dilihat juga pada presentase sebesar (21\%), dimana responden menyatakan cukup puas untuk pelayanan pada saat kapal mengalami penundaan keberangkatan yang awalnya hendak berangkat tetapi karena faktor cuaca nahkoda menunda keberangkatan kapal. Serta presentase sebesar $(25 \%)$ menyatakan puas untuk kinerja syahbandar dalam penegakkan hukum di PPI Kema, dalam hal ini petugas syahbandar tidak mengijinkan kapal untuk melaut jika surat ijin penangkapan ikan (SIPI) telah habis masa berlakunya, dan ada beberapa responden yang tidak puas $(4 \%)$ alasannya jika nahkoda atau pemilik kapal ingin mengurus SPB terhambat dengan prosesnya dikarenakan tidak adanya fasilitas penunjang seperti komputer dan printer di kantor, maka proses pengurusan SPB terlalu lama.

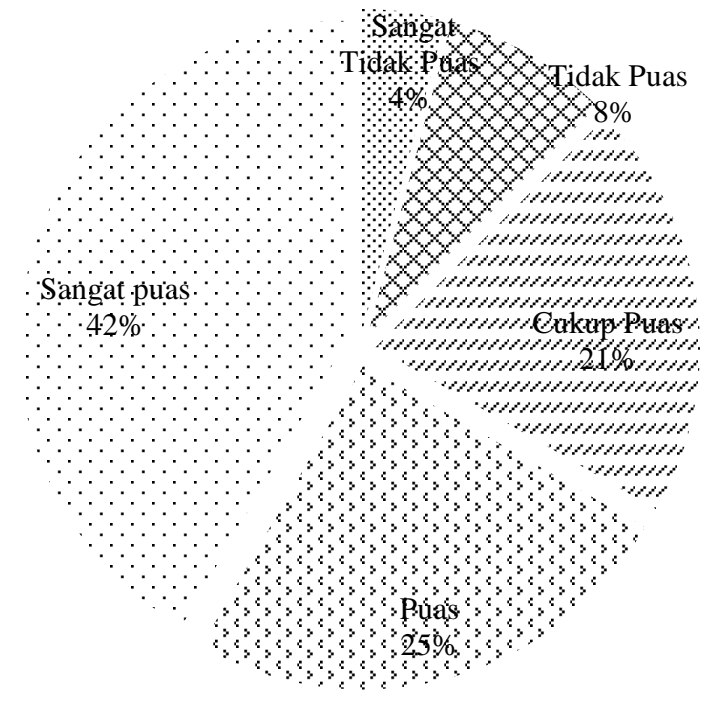

Gambar 2. Penilaian responden terhadap pelayanan Syahbandar.

\section{KESIMPULAN}

Berdasarkan hasil kajian dari tahun 2015-2018 ternyata pelayanan kesyahbandaran di Pangkalan Pendaratan Ikan (PPI) Kema, terdapat beberapa kendala dalam melayani pengurusan surat persetujuan berlayar (SPB). Meskipun demikian secara hasil evaluasi terhadap kendala yang ada maka menurut resonden sangat baik. Sehingga setiap pelayanan yang dilaksanakan oleh petugas Syahbandar tidak terlalu terganggu dengan setiap kendala yang ada.

\section{DAFTAR PUSTAKA}

Barus V, dkk. Tugas Dan Tanggung Jawab Syahbandar Dalam Kegiatan Pengangkutan Laut di Indonesia. Jurnal Volume 6, Nomor 1, Tahun 2017, Program Studi S1 Ilmu Hukum, Fakultas Hukum, Universitas Diponegoro.

Kirwelakubun N., Kayadoe. M.E., Polii. F.J., Kaparang. F.E., Pangalila. F.P.T. 2018. Studi Tentang Pelayanan Terhadap Kapal Perikanan Di Pelabuhan Perikanan Pantai (PPP) Tumumpa Kota Manado. Jurnal ITPT. Vol 3, No 1. Hal. 32-40, Juni 2018, p-ISSN 2337-4306, DOI: https://doi.org/10.35800/jitpt.3.1.2018.19377

KKP, 2013. Kesyahbandaran DiPelabuhan Perikanan. Peraturan Menteri Kelautan dan Perikanan Republik Indonesia. Peraturan Pemerintah No.3/PERMEN. $\mathrm{KP} / 2013$.

Lulul A. Anen, 2014. Penerbitan SIB,Log book dan PIPP.

Peraturan Menteri Kelautan dan Perikanan Nomor: PER.16/MEN/2006 tentang Pelabuhan Perikanan.

Rio, 2011. Kondisi dan Potensi Pengembangan Kepelabuhan Perikanan Di Kabupaten Subang. Skripsi Fakultas Perikanan Dan Ilmu Kelautan Institut Pertanian Bogor. 
A. W. E. Rante Padang dkk.

Tilik M., Budiman J., Wenno J. 2014. Analisis Musim Penangkapan Ikan Cakalang di Perairan Kepala Burung. Jurnal ITPT. Vol 1, Edisi khusus, hal. 31-37, November 2014, p-ISSN 2337-4306, DOI: https://doi.org/10.35800/jitpt.1.0.2014.6086

Turang Veni S., Kayadoe. M.E., Pangalila. F.P.T, Kaparang. F.E. 2019. Kajian Tugas Dan Wewenang Kesyahbandaran Pelabuhan Perikanan Pantai (PPP) Tumumpa. Jurnal
ITPT.Vol 4, No 1, hal. 10-15, Juni 2019, p-ISSN 23374306, DOI: https://doi.org/10.35800/jitpt.4.1.2019.22730

Undang-undang Republik Indonesia No 31 tahun 2004. Tentang Perikanan.

Undang-undang Republik Indonesia No 45 tahun 2009. Tentang perikanan, Pasal 42.

Wikipedia. 2019. Diunggah pada 15 Januari 2019 pada https://www.kanalinfo.web.id/pengertian-syahbandar. 